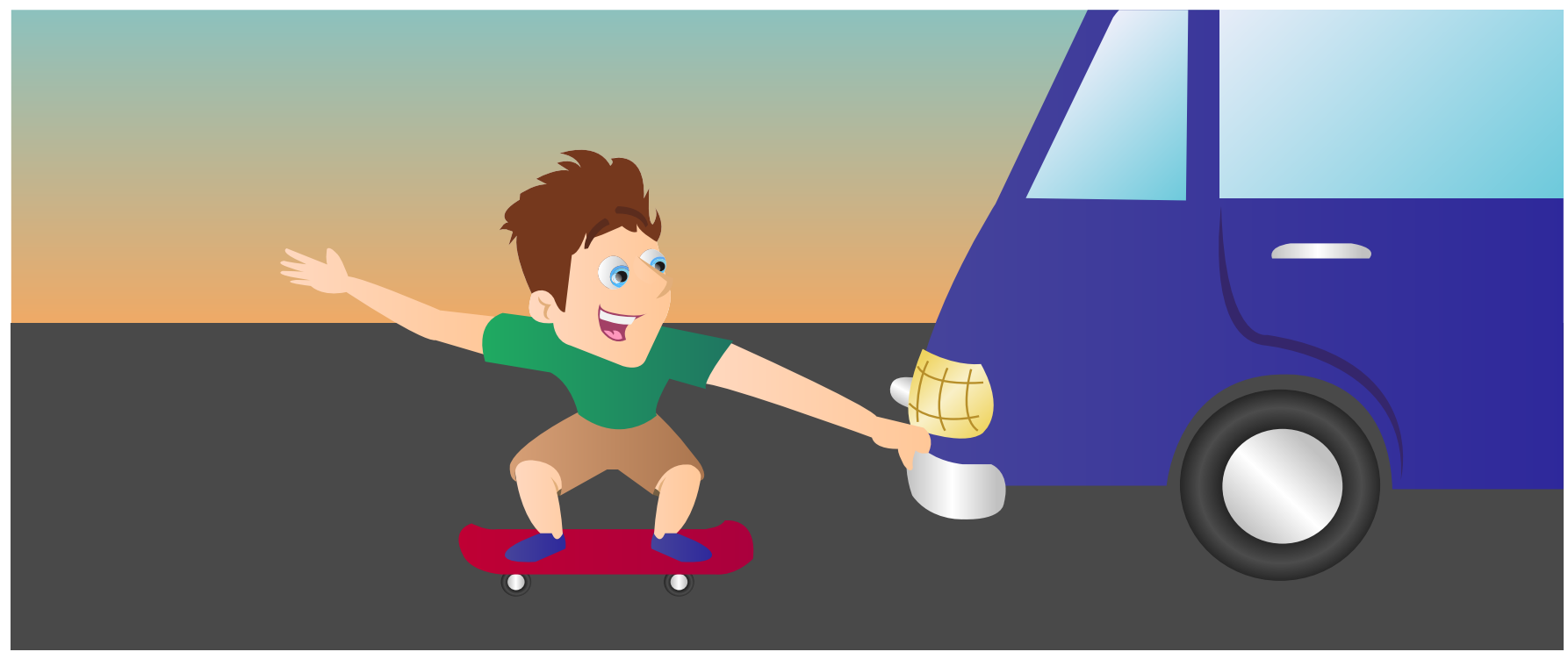

\title{
DO TEENAGERS REALLY MAKE BAD DECISIONS?
}

\section{Stacey A. Bedwell}

Department of Psychology, Birmingham City University, Birmingham, United Kingdom

\section{REVIEWED BY: \\ MANCHESTER GRAMMAR} 13-14 YEARS OLD

\section{PREFRONTAL} CORTEX

The area of the brain at the very front in humans, right behind your forehead. The area where the most complex functions are located.
Scientific research provides evidence to show that a specific area of the human brain, known as the prefrontal cortex, continues to develop much longer than other brain regions. This area is involved in a number of complex functions and actions, including our decision-making abilities. As the areas involved in making decisions do not reach full maturity until early adulthood and undergo major structural changes throughout adolescence, the way in which we make decisions can differ greatly between our teenage years and adulthood.

Have you ever wondered why teenagers are often labeled as risk takers and bad decision makers? It may seem like something your parents have made up so that they can tell you what to do, but it has some truth to it, and it all comes down to your prefrontal cortex!

The prefrontal cortex is the front-most part of the human brain (Figure 1). Most mammals have a prefrontal cortex, and this part of the brain is known to be involved in lots of complex functions, including planning for the future, decision making, goal-directed behavior (actions that you take to reach a goal you have set), and emotions. In humans, the prefrontal cortex is really something amazing. Scientists believe that the processes that take place in this region of the brain are a major contributor toward 


\section{FIGURE 1}

The location of the prefrontal cortex in the adult human brain, shown in a sagittal (side on) plane.

\section{FIGURE 2}

A typical brain processing hierarchy, indicating prefrontal cortex at the top of the hierarchy. Information is processed in the brain following an order from primary brain regions (1) through secondary brain regions (2) and finally reaching association brain regions

(3), which is the prefrontal cortex.

\section{HIGH-ORDER} PROCESS

A brain function that is positioned at the top of the processing hierarchy.

\section{PROCESSING}

\section{HIERARCHY}

A sequence or order in which brain processes/ functions take place, from the bottom up.

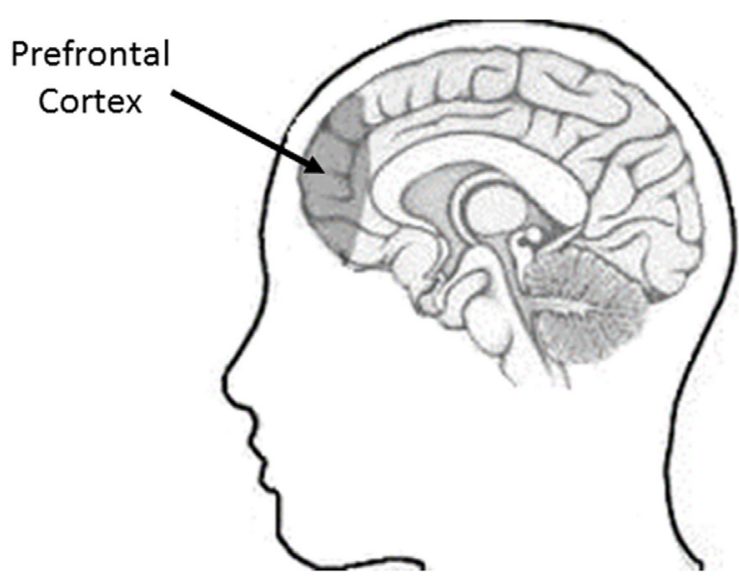

FIGURE

our advancement as a species. It is thought that it is our prefrontal cortex that "makes us human."

\section{TOP OF THE PYRAMID}

The prefrontal cortex is called an association area, which means it is involved in lots of "high-order processes"-functions that are quite complicated for your brain to do. A high-order process comes at the top of what we call the processing hierarchy (Figure 2). A processing hierarchy describes the order in which different things work together, with the most important or most complicated things at the top of the pyramid. This makes the prefrontal cortex a bit like the control center or the CEO of the brain [1].

High-order functions, like decision making, are so complicated that they require a large amount of networking between different parts of the brain: 
NEURON

Brain cell that enables the transport of information around the brain.

\section{SYNAPSE}

A connection between two neurons, through which information is transferred.

\section{SYNAPSE}

\section{PRUNING}

The removal of un-used or unnecessary connections between neurons. This process happens throughout development. many neurons (brain cells) must be connected to one another in complicated patterns in order for high-order functions to occur. The neuron networks involved in high-order functions take a long time to develop, much longer than connections elsewhere in the brain. This means that the prefrontal cortex takes a long time to reach full maturity, so we are not fully able to carry out the high-order functions associated with the prefrontal cortex until we are around 25 years old $[2,3]$ ! It may be hard to believe, but your brain really is still a work in progress throughout your teenage years and into early adulthood.

\section{CHANGES IN THE STRUCTURE OF THE BRAIN}

It is no surprise that the major changes in our abilities to do certain tasks, including making complicated decisions, come hand in hand in the structure and function of the brain. Scientists can see the structural changes using special imaging methods, like magnetic resonance imaging.

Many scientists used to believe that the human brain, including the prefrontal cortex, was mostly finished with its growth and development by the age of five or six. However, more recently, it has been discovered that structural changes in the brain happen much later in development. Giedd [1] was one of the first neuroscientists (scientists who study the brain) to see growth in the area of the prefrontal cortex around the time of puberty. Changes in the brain so late in childhood came as a surprise to many scientists. It had been understood for a long time that, in infancy, a baby's brain produces far more synapses (connections between neurons) than are needed. This is known as synapse overproduction. Children's brains go through a time of synapse pruning around the age of three. During synapse pruning, weak or un-used connections between neurons are "cut back," allowing the stronger connections to flourish and become even stronger-much like pruning a shrub or a tree. Interestingly, Giedd noticed that a similar process of synapse overproduction and pruning was occurring in the prefrontal cortex around the time of puberty (beginning approximately at the age of 11 in girls and 12 in boys).

\section{RISKY BUSINESS}

Scientists have known for a long time that decision making is associated with the prefrontal cortex, so it is no surprise that the way we make decisions changes as our prefrontal cortex develops. Because the prefrontal cortex keeps developing until our early twenties, our decision-making abilities are not fully mature until well into adulthood!

The prolonged development of decision-making networks does not mean that we are unable to make decisions until we are adults. We all know that children and teenagers make decisions about things every day. For instance, 
you decided to read this article, you decide who your friends are, what games you play, what clothes you want to wear, what TV shows you want to watch, and what you want for dinner. But, certain types of decisions do need this extra time to develop. It is these decisions that give teenagers a reputation as risk takers.

It is understood by neuroscientists and psychologists that teenagers engage in many more risky behaviors compared with adults. However, the greatest differences in risk taking between adolescents and adults depend on the type of risk involved. For instance, examples of increased risk-taking behavior and risky decisions often made by teenagers include binge drinking, smoking, casual sex, violent and criminal behaviors, careless driving, and driving under the influence of alcohol. It is thought that this difference in risky decision making in teenagers is a direct result of the changes happening in the prefrontal cortex throughout adolescence and into early adulthood [4].

So, next time you tell your mom or dad that you are old enough to make your own decisions, it might be best to re-think and take their advice. You might not be the grown up you think you are, at least when it comes to the development of decision-making networks in your prefrontal cortex!

\section{REFERENCES}

1. Giedd, J. 2002. Inside the Teenage Brain. Boston, USA: Frontline.

2. Kail, R. 1991. Developmental change in speed of processing during childhood and adolescence. Psychol. Bull. 109:490-501. doi:10.1037/0033-2909.109.3.490

3. Kail, R. 1997. Processing time, imagery, and spatial memory. J. Exp. Child Psychol. 64:67-78. doi:10.1006/jecp.1996.2337

4. Paus, T., Toro, R., Leonard, G., Lerner, J. V., Lerner, R. M., Perron, M, et al. 2008. Morphological properties of the action-observation cortical network in adolescents with low and high resistance to peer influence. Soc. Neurosci. 3:303-16. doi:10.1080/17470910701563558

SUBMITTED: 09 June 2017; ACCEPTED: 01 September 2017; PUBLISHED ONLINE: 27 September 2017.

EDITED BY: Sabine Kastner, Princeton University, United States

CITATION: Bedwell SA (2017) Do Teenagers Really Make Bad Decisions? Front. Young Minds 5:53. doi:10.3389/frym.2017.00053

CONFLICT OF INTEREST STATEMENT: The author declares that the research was conducted in the absence of any commercial or financial relationships that could be construed as a potential conflict of interest. 
COPYRIGHT () 2017 Bedwell. This is an open-access article distributed under the terms of the Creative Commons Attribution License (CC BY). The use, distribution or reproduction in other forums is permitted, provided the original author(s) or licensor are credited and that the original publication in this journal is cited, in accordance with accepted academic practice. No use, distribution or reproduction is permitted which does not comply with these terms.

\section{REVIEWED BY}

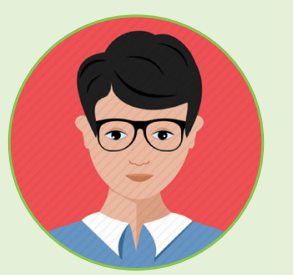

\section{MANCHESTER GRAMMAR}

I love science and reading science fiction novels. Reviewing science articles is a great way of combining both my interests.

\section{AUTHOR}

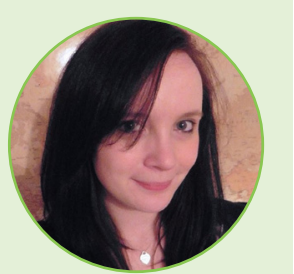

\section{STACEY A. BEDWELL}

Dr. Stacey A. Bedwell is a Lecturer in Psychology at Birmingham City University and has a Ph.D. in neuroscience. Stacey does research into how the human brain works and how it enables us to do complicated tasks like making decisions, planning things in the future, and working toward goals. Stacey is the author and illustrator of children's neuroscience book "How does my brain work?". *stacey.bedwell@bcu.ac.uk 